\title{
THE CRUSHED CHEST
}

\author{
BY \\ HARRY M. WINDSOR AND BRIAN DWYER \\ From St. Vincent's Hospital, Sydney
}

The primary object of this paper is to consider the management of the badly crushed chest.

At St. Vincent's Hospital, Sydney, about 20 patients with moderate to severe chest injuries are admitted each year. Our original analysis of the mortality and morbidity of 200 such cases in the past eight years led us to believe that the methods of complete control to be outlined in this paper could be used with advantage about three times in every 40 cases, and in the past two years we used them on five occasions. Partial control is now being used more and more frequently in cases with injuries causing less severe paradox. The decision as to when completely to control respiration is difficult. In general it is carried out when paradox is so severe that it cannot be controlled by simple means. This is illustrated in Cases 1 and 2 of the following case reports.

\section{CASE Reports}

CASE 1.-S. de K. (57/2490), a powerfully built man of 42 years, was involved in a car accident on November 16, 1957. He was seen by one of us $(H$. W.) the next day. He had what could only be described as a "wobbly" chest. Many ribs on both sides were fractured, some in two places. He had a small haemothorax, but no pneumothorax, and no significant injury elsewhere. Paradoxical respiration was severe and bilateral. He was extremely dyspnoeic. The injury was not in itself fatal, but the paradox was uncontrollable by simple means. Unfortunately, he was in the Snowy Mountains, 350 miles from Sydney, and he was considered too ill to move at the time. This proved to be wrong, for, when two days later he was still alive and the decision to move him was made, he survived a two-hour bumpy trip in a small plane.

He was admitted to St. Vincent's Hospital at 3 p.m. on November 19 . The inevitable had happened. The lungs were wet and opaque, and paradox was extreme.

Respiratory paralysis was at once induced and controlled respiration through a tracheostomy was begun. It was too late, because adequate ventilation could not be achieved on account of widespread consolidation. The patient died the next day.

Necropsy revealed little other than the comminuted rib fractures (fractures of 24 ribs) with a number of floating segments. Death was due solely to the results of paradoxical respiration. A critical inspection of the many scattered fractures demonstrated how fruitless any endeavour to control the paradox by mechanical fixation would have been.

This, then, is the type of case we see about three times in every 40 cases of moderate to severe chest injury. It illustrates what we mean by severe and dangerous paradox.

CASE 2.-In this case the injuries were more extensive and serious than in Case 1. It is reported in detail in order to elaborate the method of control of the paradox and to emphasize the application of modern thoracic surgical and anaesthetic principles to severe chest injuries.

An American, D. McN. (58/1939), aged 44, was involved in a head-on collision at 12.5 a.m. on October 19, 1958. He received the full impact of the steering column in the chest. He was admitted to Manly Hospital under the care of Mr. Malcolm Stanley and was first seen by one of us (H.W.) 14 hours after the accident.

At that time he was lying supine. He was semiconscious, cyanosed, and extremely dyspnoeic. He had gross, generalized, surgical emphysema with violent, piston-like, paradoxical movement of the right upper anterior chest and sternal regions. Control of the paradox had been attempted by the use of a hook attached to an overhead frame and inserted into an upper right anterior rib. Radiographs of the chest showed a right haemopneumothorax which had been treated by a needle in the right pleural cavity. Bronchial obstruction due to secretions was marked. An abdominal injury was suspected, but a satisfactory examination was impossible at this time due to the patient's dyspnoea, paradox, and confused mental state. He also had a compound fracture of the shaft of the right femur and a comminuted fracture of the right femoral trochanter. The tongue had received a large ragged laceration, and most of the front teeth had been knocked out. The pulse rate was 100 per minute and the respirations 32 per minute. Morphia, $96 \mathrm{mg}$., pethidine, $50 \mathrm{mg}$., pethilorfan, $100 \mathrm{mg}$., and paraldehyde, $10 \mathrm{ml}$., had been given in an effort to control pain and restlessness. 
It appeared to be absolutely necessary to control the paradoxical respiration and seemed to be possible only by abolishing the patient's spontaneous respiration with a muscle relaxant and instituting intermittent positive pressure respiration. To do this, it was considered essential to transfer the patient, even at great risk, to a thoracic surgical unit. He was admitted to St. Vincent's Hospital at 4.15 p.m. on October 19. He was then cyanosed and restless, with frightening paradox and gross bronchial obstruction from secretions.

The management was as follows:

Bronchoscopy.-This was done without anaesthesia, and almost proved fatal. The trachea and bronchi were full of blood and solid particles of vomit. The distal light on the bronchoscope rapidly became occluded, blood collected again, and the suckers soon blocked. The patient became deeply cyanosed and pulseless.

Intubation with a Cuffed Endotracheal Tube.-This was done the moment it became obvious that persisting with the bronchoscopy would be fatal. This resulted in more satisfactory ventilation, and further removal of intrabronchial blood was possible.

Tracheostomy and Insertion of Short Cuffed Endotracheal Tube.-A large tracheostomy was made and more blood and vomit were removed.

Full Curarization and Controlled Respiration.Immediately these steps were completed paradox was controlled, but difficulty in maintaining adequate ventilation was noted because of (1) increased resistance to inflation, which a radiograph in the theatre showed to be due to a large right haemopneumothorax (the original decompressing needle having blocked). This was decompressed by a large intercostal catheter which drained $20 \mathrm{oz}$. of blood. The catheter was then connected to a suction pump and the lung re-expanded. There was no continuous air leak from this pleural cavity. (2) An enormous increase in the surgical emphysema developed, and when small incisions were made beneath the clavicles air hissed out with each squeeze of the bag. It also escaped freely around the tracheostomy so that using a " closed circuit" flow rates up to 10 litres per minute were required to maintain ventilation. Such a leak could only come from a major air passage.

Operation.-At 9.15 p.m. a transverse incision was made at the level of the third rib. The moment the subcutaneous tissues were incised, gusts of air obtruded with every squeeze of the bag. The anatomy of the bony injury could now be seen. There was a comminuted fracture of the manubriosternal junction, the ends being 2 in. apart; there were comminuted fractures of the anterior ends of the upper right ribs; and the right sterno-clavicular joint was completely disrupted, leaving a gap of 2 in. The manubrium was attached to the left clavicle. The mediastinum lay bare.

A rib spreader was inserted. It was at once apparent that the air was issuing from deep in the mediastinum via a dirty discoloured tract. Stomach contents, including a few shreds of onion, were present in the mediastinum. At this stage it was almost impossible to keep the lungs inflated because of the large air leak, and further blood accumulated in the tracheobronchial tree due to the blood from inflamed mediastinal tissues pouring through the air leak. A large pack was placed in the mediastinum, and this resulted in improved anaesthetic conditions. The next difficulty was finding the hole. The left innominate vein was stretched taut across the mediastinum and interfered with exposure, so it was at once ligated and divided. The innominate artery and aortic arch could then be retracted to the left when the site of the air leak became apparent. There was a tear $1 \frac{1}{2}$ in. long in the trachea situated at the junction of membranous and cartilaginous portions 1 in. above the bifurcation on the right side. The depth of the wound made closure difficult, but it was achieved with interrupted black silk sutures. It was out of the question to alter the site of the incision to facilitate exposure. At once the anaesthetic problem became less troublesome, and it was a little easier to keep the trachea and bronchi dry.

The sternum was wired to the manubrium and the manubrium to the clavicle and first rib. This resulted in some degree of stabilization. The wound was closed in layers with one tube in the right pleural cavity and a second in the mediastinum.

The immediate post-operative period was difficult. Blood, secretions, and inhaled vomit were still present and bronchoscopy was again necessary, this time through the tracheostomy. It was hurriedly done because the moment assisted respiration was discontinued the patient became deeply cyanosed. However, major secretions were cleared. The cuffed tube was reinserted and assisted respiration continued. Immediately afterwards further difficulty in maintaining adequate ventilation was experienced due to a left pneumothorax. At operation the left pleural cavity did not appear to have been opened, so no tube had been left in that side. This was rectified.

The problem now was to decide how to maintain adequate respiration. $A$ radiograph taken in the theatre showed both lungs fully expanded, though the right lung was extensively consolidated and the left one less so. The trachea had been sutured and the chest wall stabilized, so it was anticipated that paradox would be of less significance. In succession the following measures were adopted:

Maintaining Respiration.-The patient was allowed to breathe spontaneously, but in a few seconds this was seen to be impossible. The paradox, despite mechanical fixation, was severe, the breaths were convulsive gasps, bronchospasm was marked, and intense cyanosis developed.

Manually assisted respiration, using oxygen (100\%) at a respiratory rate of 40 to 44 , maintained life, but its rapidity made it impossible to synchronize the rebreathing bag with the patient's respiration. The 
paradox was unchecked and anoxia and carbon dioxide retention developed.

A Bennett's respirator, using $100 \%$ oxygen and maximal inspiratory pressures $(20-25 \mathrm{~cm}$. of water), was next tried unsuccessfully. The secretions, the paradox, and the intense bronchospasm provided such a degree of respiratory obstruction that these maximum inflationary pressures were too low, and cyanosis, sweating, and a raised blood pressure resulted.

Complete curarization and intermittent positive pressure respiration proved the only method of controlling the shattering paradox and providing adequate ventilation. The patient's colour improved, the pulse rate dropped to 100 , and the blood pressure dropped to within normal limits. Constantly recurring copious secretions and intense bronchospasm persistently caused great concern, as the inflationary pressures needed $(35 \mathrm{~cm}$. of water) remained very high and rendered two mechanical respirators (the Harrington-James and the Jefferson) ineffectual. Manual control of respiration with complete paralysis was therefore essential and was carried out with a standard Boyle's anaesthetic machine and circle type $\mathrm{CO}_{2}$ absorption. This was continued throughout the night and during the next day, at a rate of 40 per minute at a pressure of $20-35 \mathrm{~cm}$. of water.

The above measures, with frequent tracheobronchial toilet, controlled the respiratory difficulties, although each bronchial suck-out was accompanied by cyanosis, sweating, and a rise in blood pressure.

At 6.30 p.m. on the first post-operative day atropine, $1 \mathrm{mg}$., and "prostigmin," $2.5 \mathrm{mg}$., were given to reverse the curare and observe any change in respiratory efficiency. Paradox was still severe and both spontaneous respiration and assisted respiration were inadequate.

At 7.30 p.m. the patient's condition had deteriorated, and he had a pulse rate of 150 and a blood pressure of $85 \mathrm{~mm}$. of mercury. Controlled respiration was restarted. The blood pressure at once rose to $130 \mathrm{~mm}$. of mercury. Fluctuations in pulse and blood pressure recurred frequently throughout the night. The soda lime had to be changed at 15-minute intervals. Pethidine, soluble phenobarbitone, and a nitrous oxide-oxygen mixture $(50 \%)$ sedated the patient.

Controlled respiration was continued in the second post-operative day, but as the curare wore off it was found that respiration could be manually assisted. Despite this, in the early afternoon the patient's condition was poor and his pulse rate was 144 . The inflation rate was 46 and it was virtually impossible to clear the bronchial tree. A bronchoscopy resulted in some improvement.

At 6 p.m. the curare was reversed and a further attempt at spontaneous respiration made. It was unsuccessful, as also was assisted respiration. Controlled respiration was induced and maintained throughout the night. During the period of reversal the first signs of returning consciousness appeared. The patient opened an eye and gazed with a sightless stare. He did, however, respond to painful stimuli.
On the third post-operative day there was further improvement in the conscious state. Manually assisted respiration with smaller intermittent doses of curare was a little easier to maintain, and an attempt to induce spontaneous respiration was a little more successful. This time it lasted 40 seconds before the patient became distressed. Throughout the night controlled respiration was continued.

On the fourth post-operative day a chest radiograph showed extensive bilateral pneumonia. Throughout the day mechanically assisted respiration with a Bennett's respirator using a $60 \%$ oxygen-air mixture was alternated with manually assisted respiration. Inflationary pressures were still high $(20-25 \mathrm{~cm}$. of mercury). Alevaire and neo-epinine added to the inspired mixture helped to diminish the bronchospasm.

A further attempt at spontaneous respiration was made. There was an improved response, the patient breathing spontaneously for one minute. Throughout the night, to prevent exhaustion and for the sake of safety, respiration was alternately manually controlled or assisted.

This progressive pattern continued for some days. the paradoxical respiration gradually lessened, but severe bronchospasm, secretions, and inhalation pneumonia made assisted respiration of some form necessary. Alevaire, neo-epinine, adrenaline in oil, and an intravenous aminophylline drip were all used and ultimately helped in combating these features. Constant tracheobronchial suction, although distressing to the patient, was absolutely essential every hour and sometimes more often.

Each day spontaneous respiration continued for a little longer. On the seventh post-operative day it continued for 20 minutes. It was then felt safe to move the patient from the recovery ward, and this was done on the eighth post-operative day, but the short trip to his room proved most distressing and assisted respiration was necessary for some hours. Throughout the night mechanically assisted respiration was continued. This was the first night that either manually assisted or controlled respiration was unnecessary.

On the ninth post-operative day assisted respiration through a cuffed tube was alternated with spontaneous respiration through a metal tracheostomy tube. At 11 p.m. on this day, while the metal tube was in place, bronchospasm suddenly became severe and secretions copious. This had been initiated by the passage of a duodenal tube a few minutes earlier. The metal tube was removed in order to carry out bronchial toilet. Just as the tube was removed the patient vomited. He inhaled a considerable quantity and at once became unconscious and pulseless. The vomit was sucked out, the cuffed tube was reinserted, and manual inflation with $100 \%$ oxygen begun. His pulse returned and blood pressure rose to $250 \mathrm{~mm}$. of mercury. At no stage had he been without a doctor in attendance. This factor alone saved him on this occasion. Slow improvement took place and three hours later he was asleep and his colour quite reasonable. 
On the eleventh post-operative day his condition gradually deteriorated throughout the morning. He had great respiratory difficulty, assisted respiration again becoming necessary. The chest radiograph was worse than ever. Both pleural cavities were needled and $26 \mathrm{oz}$. of blood-stained fluid removed from the left side. A further bronchoscopy was necessary when the entire bronchial tree was seen to be red and dotted with pyogenic membrane. Loose debris was removed. These measures resulted in some improvement and this was reflected in improving chest radiographs.

Progress was now rapid, and on the fourteenth postoperative day the patient breathed spontaneously for 24 hours. The tracheostomy was kept open with a large plastic tube for a further two weeks, as the cough was quite inadequate to remove bronchial secretions. He was discharged on January 8, 1959.

We have deliberately avoided mentioning the problems confronting us with regard to the abdominal injury, the femoral fractures, and the mediastinal infection.

CASE 3.-J. H. (59/555), a man aged 73, was involved in a car accident on July 30, 1959 . On admission he was stuporose, anoxic, hyperpnoeic, with gross paradox of the entire right anterior chest and axilla. There were multiple fractures of the second to eighth ribs on the right and surgical emphysema of the face, chest, and upper abdomen. The abdomen was very distended. The pulse rate was $106 / \mathrm{min}$. and the blood pressure $85 \mathrm{~mm}$. $\mathrm{Hg}$. A chest radiograph revealed a right haemopneumothorax with patchy atelectasis on the left side.

The patient was given a general anaesthetic and curarized, a large amount of blood-stained mucus first being removed from the bronchial tree. Paradox was abolished at once. An intercostal catheter was inserted into the right side of the chest and $22 \mathrm{oz}$. of blood removed. The lung re-expanded. A tracheostomy was performed and further blood-stained mucus obtained.

After these procedures a period of three hours was spent in converting the patient from manually controlled respiration to mechanically assisted respiration. As in Case 2, he was at first unable to adjust to the mechanical respirator due to secretions and spasm, but at the end of three hours he was comfortable with paradox controlled at 15 to $20 \mathrm{~cm} . \mathrm{H}_{2} \mathrm{O}$ on a Bennett's respirator. In the ensuing three days improvement was steady, though periods of $\mathrm{CO}_{2}$ retention with rises in blood pressure necessitated frequent distressing tracheal suction.

On August 4, 1959, four days after admission at 6.30 a.m. his condition suddenly deteriorated. A radiograph of the chest revealed a right effusion and some left-sided consolidation. His pulse was $180 / \mathrm{min}$., his blood pressure was unrecordable. He was moribund, in profound circulatory failure, though neither cyanosed nor sweating. A change from mechanical to manually assisted respiration was unavailing. A right chest aspiration produced 1,000 ml. of blood without improvement and tracheal suction failed to improve his condition. However, considerable resistance to manual inflation was observed, so the cuffed tube was removed. At one end of the tube was a tough flap of adherent fibrin and old clot, acting as a valve. It allowed the sucker to pass through but at once flapped into place. A clean tube was inserted and the respirator restarted. Improvement began at once and was maintained. Recovery was then rapid. The patient was discharged on August 25, 1959.

CASE 4.-H. T. (59/4276), a man aged 38, was injured in a head-on collision on February 26, 1960. He suffered multiple fractures of the anterior ends of the left second to seventh ribs, a transverse fracture of the sternum, and a compound fracture of the left tibia and fibula. The right forearm and hand were virtually roasted. He was admitted to the Hornsby Hospital under the care of Mr. W. Taylor.

He was found to have a left haemothorax and severe bilateral paradox. He was transferred to the Thoracic Surgical Unit at St. Vincent's Hospital. On admission an intercostal catheter was inserted into the left chest, $1,500 \mathrm{ml}$. blood was removed, and the left lung re-expanded. Paradox was still gross, so he was given a general anaesthetic and curarized. A tracheostomy was performed and controlled respiration instituted. The conversion period from controlled to mechanically assisted respiration lasted two hours.

Next morning he again had considerable difficulty with paradox. A radiograph of the chest revealed a right pneumothorax, which was corrected and the paradox disappeared.

The patient ran a swinging temperature $\left(100^{\circ}\right.$ F.$102^{\circ}$ F.) from admission. A radiograph of the chest on March 10 revealed a large left effusion, which proved to contain pus, and on March 11 a left total empyema was drained. Despite this, his condition deteriorated. On March 14 he developed atrial fibrillation with a rate of 160 ; he was disorientated, and there was a pericardial friction rub. A radiograph of the chest showed a distended pericardium, which was needled and heavily blood-stained offensive fluid withdrawn. A smear contained Gram-positive cocci. The pericardium was at once drained. The blood culture grew a haemolytic Staphylococcus aureus. Heavy doses of chloromycetin and erythromycin were begun. Thereafter the patient made a good recovery, though it was many months before he had a useful right hand.

We considered that the lesions predisposing to the septicaemia and suppurative pericarditis were the fractured sternum and the extremely infected forearm and hand.

CAse 5.-Mrs. J.P. (131/60), aged 38 years, was standing beside a traffic signal with her two children when all three were hit by a semi-trailer. The daughter was killed. The son is the subject of Case 6 .

She was admitted to Lewisham Hospital in a severely shocked and stuporose state. The skin had 
been virtually torn from both legs below the knees. This, apparently, was looked upon as the major consideration. She was transfused and taken to the operating room. During the course of the anaesthetic the anaesthetist noted increasing difficulty in inflating the chest and a little later noted gross bulging of the right anterior chest followed quickly by extensive surgical emphysema. Further difficulty was experienced following the appearance of considerable quantities of blood-stained sputum.

She was seen by one of us (H.W.) at this stage. $A$ radiograph in the theatre demonstrated multiple right upper rib fractures, a right haemopneumothorax with tension and mediastinal shift, and a contused left upper lobe.

An intercostal catheter was inserted into the left chest and $14 \mathrm{oz}$. of blood removed, after which the catheter was connected to a suction pump. The lung re-expanded. A tracheostomy was performed. At the end of the operation on the legs a conversion period of seven hours was necessary before the change from manually controlled to mechanically assisted respiration was complete. Bloody sputum from the contused left lung and a fracture dislocation of the first lumbar vertebra with corda equina symptoms necessitating recumbency were two other factors which made conversion troublesome.

As soon as stabilization with a Bennett's respirator was achieved progress so far as the chest was concerned was excellent. A radiograph taken on the fifth post-operative day showed complete expansion of the right lung and clearing of the contused left upper lobe.

Open reduction of the lumbar vertebra was carried out on March 10. After this progress was satisfactory, although the leg injuries delayed the patient's departure from hospital for many months.

CASE 6.-D.P. (2548/59), a boy aged 7, was admitted to Lewisham Hospital on March 2, 1960. He had been knocked down by a semi-trailer a few minutes earlier. His pulse was 120 and blood pressure $105 / 60 \mathrm{~mm}$. Hg. The right lower chest and abdomen were badly bruised. A radiograph of the chest demonstrated some contusion of the right upper lobe.

During the night the pulse rate rose to $140 / \mathrm{min}$. and the blood pressure dropped to $95 \mathrm{~mm}$. $\mathrm{Hg}$. The respirations became increasingly shallow and grunting. A chest radiograph early the next morning demonstrated a fluid level at the right base. In a further radiograph two hours later the level had increased in size. There was neither cough nor sputum.

Right thoracotomy was performed at once. The pleura over the lower lobe was intact, but the lobe was virtually gangrenous. It was excavated and filled with blood clot. The upper lobe was moderately contused. A lower lobectomy was carried out. Convalescence was satisfactory and the boy was discharged 10 days later.

CASE 7.-Mrs. L. A. $(610 / 60)$, aged 49, was admitted to St. Vincent's Hospital on July 31, 1960. A car crashed head on into the side of the car in which she was travelling and she received the full impact on the left side.

On admission she was dyspnoeic and cyanosed. The left side of her chest was "wobbly." A radiograph revealed what was virtually a left thoracoplasty. The left clavicle was fractured.

A tracheostomy was performed at once and mechanically assisted respiration begun. The paradox was controlled within five minutes. During the next few days the physiological disturbance was well controlled. Thirty-six hours after admission a left pneumothorax occurred which necessitated an intercostal catheter. At the end of 10 days it was still present and air was still leaking. For this reason left thoracotomy was performed. Five sharp spikes of ribs were projecting into various parts of the lung. These were removed and the pulmonary lacerations oversewn, and an attempt made to wire the chest. Although six of the fragments were wired, the futility of the procedure was soon apparent and the attempt was discontinued.

Respiration was mechanically assisted for two days after operation. It was then discontinued because paradox was fully controlled and the lung completely expanded. Thereafter recovery was rapid. She was discharged on September 4, 1960.

CASE 8.-R. L. (578/60), a man aged 50, was involved in a car accident on May 29, 1960.

On admission he was deeply unconscious with a fixed dilated pupil. There were extensive scalp lacerations and multiple left rib fractures, severe paradox, and left pneumothorax.

Parietal burr holes were made, but neither extradural nor subdural haematomata were found. $\mathrm{He}$ was considered to have extensive cerebral damage with brain swelling, and his prognosis was regarded as bad.

Despite the cerebral state the left chest was decompressed, a tracheostomy was performed, and paradox was controlled by assisted respiration.

The response to the establishment of normal respiration was immediate. Withın minutes the state of consciousness improved and in an hour he was conscious and co-operative. He made an uneventful recovery.

\section{COMMENT}

AIR LEAK.-The air leak is either into the mediastinum and tissues or into the pleural cavity. In the case of a pneumothorax, even if the leak is continuous, management by means of an intercostal catheter and suction pump is a simple matter. If the air leak is severe and continuous, management is a different problem, for then the assumption must be that the size of the opening is large or the site of the opening is probably in a major air passage.

Size of the Opening.-In Case 2 it was not apparent that the air leak was large until such 
time as an attempt at controlled respiration had been made. The increasing emphysema and the leak of air from the small subclavicular incisions were then obvious with every squeeze of the bag.

Site of Leak.-Upon the site of the leak will depend where air will appear. Rupture of the right bronchus or distal left bronchus, both associated, as they are, with the reflection of visceral pleura on to the mediastinum, will almost certainly produce either a right or left pneumothorax. There are many reports of such cases. Rupture of the trachea or proximal left bronchus, much more deeply placed, will always produce mediastinal emphysema but not always pneumothorax. Ten reported cases of tracheal rupture have been found in the literature (Table I). Of these, six had mediastinal emphysema alone, two had mediastinal emphysema and pneumothorax, and in two it was difficult to be sure.

The surgical approach of bilateral anterior thoracotomy in Case 2 was decided upon after consideration of the following points: (1) The ballooning of the sternal area with each inflation suggested the mediastinum as the site of the leak. (2) The absence of a continuous leak of air into the right pleural cavity suggested that the opening was above the right bronchus. (3) It was impossible to make an adequate tracheobronchial inspection with a bronchoscope. (4) There appeared to be some possibility of controlling the paradox by fixing the fragments with wire. (5) Respiration was best controlled and maintained with the patient supine.

There are insidious forms of air leak with which we are being continually confronted. In these cases the patient is admitted without a pneumothorax but suddenly, hours or days after admission, develops severe tension, or the patient is admitted with a crushed chest and pneumothorax. Partial control of respiration with a respirator is instituted, but some hours later he becomes distressed and is found to have a contralateral pneumothorax (Case 4). Or the patient is admitted with severe multiple injuries and for some reason is submitted to general anaesthesia without the true nature of the chest injury being realized.

TABLE I

SUMMARY OF CASES OF TRACHEAL RUPTURE

\begin{tabular}{|c|c|c|c|c|c|c|c|c|c|}
\hline Author & Age & Sex & Cause & Clinical Aspects & Diagnosis & Pathology & Treatment & Post-operative & Result \\
\hline $\begin{array}{c}\text { Barford } \\
(1906)\end{array}$ & 4 & $\mathbf{M}$ & $\cdots$ & $\begin{array}{l}\text { Surgical } \\
\text { emphysema } \\
\text { without } \\
\text { pneumothorax }\end{array}$ & - & $\begin{array}{l}\text { Left bronchus } \\
\text { detached from } \\
\text { trachea. Tracheal } \\
\text { rupture }\end{array}$ & $\mathrm{Nil}$ & & Death \\
\hline $\begin{array}{l}\text { Bickford } \\
\text { and } \\
\text { Robertson } \\
(1958)\end{array}$ & $\begin{array}{r}\text { Young } \\
\text { adult }\end{array}$ & $\mathbf{M}$ & $\begin{array}{c}\text { Steering } \\
\text { wheel }\end{array}$ & $\begin{array}{l}\text { Surgical } \\
\text { emphysema and } \\
\text { pneumothorax } \\
\text { on the fourth } \\
\text { day }\end{array}$ & $\begin{array}{l}\text { On fourth day } \\
\text { when lear seen } \\
\text { at broncho- } \\
\text { scopy }\end{array}$ & $\begin{array}{l}\text { Rupture on the } \\
\text { right side at junc- } \\
\text { tion of mem- } \\
\text { branous and } \\
\text { cartilaginous } \\
\text { parts }\end{array}$ & $\begin{array}{l}\text { Right thora- } \\
\text { cotomy and } \\
\text { closure of the } \\
\text { rent }\end{array}$ & $\begin{array}{l}\text { Spasm for } 30 \\
\text { min. post- } \\
\text { operatively } \\
\text { before } \\
\text { spontaneous } \\
\text { respiration }\end{array}$ & Recovery \\
\hline $\begin{array}{l}\text { Dark and } \\
\text { Dewsbury } \\
(1955)\end{array}$ & 6 & $\mathbf{M}$ & Fell $10 \mathrm{ft}$ & $\begin{array}{l}\text { Surgical } \\
\text { emphysema, } \\
\text { right pneumo- } \\
\text { thorax }\end{array}$ & $\begin{array}{l}\text { On clinical } \\
\text { grounds }\end{array}$ & - & $\begin{array}{l}\text { Right thora- } \\
\text { cotomy with } \\
\text { right upper } \\
\text { lobectomy } \\
\text { and tracheal } \\
\text { repair }\end{array}$ & & Recovery \\
\hline $\begin{array}{l}\text { Moty and } \\
\text { Guibal } \\
\text { (1907) }\end{array}$ & & $\mathbf{M}$ & & $\begin{array}{l}\text { Surgical } \\
\text { emphysema } \\
\text { without } \\
\text { pneumothorax }\end{array}$ & & $\begin{array}{l}\text { Both bronchi } \\
\text { separated from } \\
\text { trachea }\end{array}$ & Nil & & Died \\
\hline $\begin{array}{r}\text { Patrick } \\
(1917)\end{array}$ & 34 & $\mathbf{M}$ & & $\begin{array}{l}\text { Surgical } \\
\text { emphysema } \\
\text { without } \\
\text { pneumothorax }\end{array}$ & & $\begin{array}{l}\text { Left bronchus } \\
\text { detached from } \\
\text { trachea }\end{array}$ & Nil & - & Died \\
\hline $\begin{array}{l}\text { Richards } \\
\text { and Cohn } \\
(1955)\end{array}$ & & $\mathbf{M}$ & $\begin{array}{l}\text { Car } \\
\text { accident }\end{array}$ & $\begin{array}{l}\text { Surgical } \\
\text { emphysema } \\
\text { without } \\
\text { pneumothorax }\end{array}$ & $\begin{array}{l}\text { Bronchoscopy } \\
\text { and finding a } \\
\text { stricture }\end{array}$ & - & $\begin{array}{l}\text { Permanent } \\
\text { tracheotomy }\end{array}$ & - & Alive \\
\hline $\begin{array}{l}\text { Rolleston } \\
\text { (1891) }\end{array}$ & & $\mathbf{M}$ & & & & $\begin{array}{l}\text { Rupture of trachea } \\
\text { and pulmonary } \\
\text { artery }\end{array}$ & Nil & & Died \\
\hline $\begin{array}{l}\text { Schönberg } \\
\text { (1912) }\end{array}$ & 20 & $\mathbf{M}$ & $\begin{array}{l}\text { Caught } \\
\text { between } \\
\text { buffers }\end{array}$ & & & $\begin{array}{l}\text { Trachea trans- } \\
\text { versely severed }\end{array}$ & Nil & & Died \\
\hline $\begin{array}{l}\text { Seuve } \\
(1873)\end{array}$ & 74 & $\mathbf{M}$ & $\begin{array}{l}\text { Wheel of } \\
\text { bus over } \\
\text { chest }\end{array}$ & $\begin{array}{l}\text { Surgical } \\
\text { emphysema }\end{array}$ & & Ruptured trachea & Nil & & Died \\
\hline $\begin{array}{l}\text { Thompson } \\
\text { and Eaton } \\
(1955)\end{array}$ & 34 & $\mathbf{M}$ & $\begin{array}{l}\text { Crushed } \\
\text { by } \\
\text { concrete } \\
\text { tile }\end{array}$ & $\begin{array}{l}\text { Right pneumo- } \\
\text { thorax, little } \\
\text { surgical } \\
\text { emphysema }\end{array}$ & $\begin{array}{l}\text { On clinical } \\
\text { aspects }\end{array}$ & & $\begin{array}{l}\text { Right thora- } \\
\text { cotomy with } \\
\text { right upper } \\
\text { lobectomy } \\
\text { and repair of } \\
\text { trachea }\end{array}$ & & Recovery \\
\hline
\end{tabular}


During the operation the anaesthetist finds the condition deteriorating and cannot inflate. A radiograph on the table reveals a unilateral or bilateral pneumothorax (Case 5). Although there is nothing particularly new in these phenomena, they are becoming more frequent and we cannot help but feel they are associated with the increasing use of positive pressure breathing. They are of little significance if recognized and managed promptly. To facilitate this a chest radiograph should be taken as soon as positive pressure breathing has begun, and repeated in six hours.

Paradoxical Respiration.-When the chest wall is disrupted it leads to paradoxical respiration of a degree proportional to the degree of disruption. Severe paradox is tantamount to an open sucking pneumothorax; it can be fatal, and is certainly the most difficult of all the mechanical disturbances associated with chest injury to correct. Most cases can be dealt with by the simple measures of sand-bagging and strapping

Much has been written on the methods of fixing the thoracic cage by means of wire and various forms of splinting. It is our feeling that if the flail chest wall can be stabilized by such methods, then the degree of trauma is not severe and control can be achieved by simpler methods. We feel that internal surgical fixation ought to be confined to certain sternal injuries. On the other hand, injuries involving multiple bilateral comminuted rib fractures with gross paradox can never be stabilized by internal fixation but require immediate control of respiratory movements. The patient must be rendered apnoeic by some means, and intermittent positive pressure respiration begun. Avery, Mörch, and Benson (1956) did this by hyperventilation with a high-capacity respirator. We found that it could be simply done with intermittent doses of curare $(5-10 \mathrm{mg}$. every 30 to 40 minutes) and moderate hyperventilation by normal squeezing of the rebreathing bag of a standard anaesthetic machine. We found in Case 2 (despite the wire) that assisted respiration, either manual or mechanical, would not control the paradox and maintain an adequate minute volume. Similarly, in the early stages we found mechanical respirators unsatisfactory. Only manual compression of the bag at 40 per minute with high inspiratory pressure was adequate. This method provided a far more sensitive control over the constantly changing respiratory pattern.

Patients with such severe injuries require continuous medical supervision, so this manual control is no great additional burden.

In Case 2, as each day passed paradox diminished, and as stability improved and bronchial obstruc- tion lessened it was possible to gain a little co-operation from the patient. $\mathrm{He}$ was first introduced to manually assisted respiration, then mechanically assisted respiration (Bennett), using at first $100 \%$ oxygen and then a $40 \%$ mixture in air. Further improvement was noted by the gradual reduction in the inflationary pressures required. Finally, assistance to respiration was confined to the nights to allow the patient to recover from the exhaustion of breathing all day.

In Cases 3, 4, 5, and 7, although the paradox was gross, inhalation, spasm, and secretions were not troublesome and far less curare was used. Manually controlled respiration was continued for a much shorter time and it was easier to stabilize the chest with mechanically assisted respiration.

The most difficult period is the change-over from manually controlled (where it has proved necessary) to mechanically assisted respiration. At one end of the scale is the patient who is fully conscious, has no bronchospasm and little secretion. A simple explanation, encouragement, and a little patience are all that is necessary. At the other end of the scale is Case 2, where the transition lasted one week.

The change from hyperpnoea, cyanosis, and paradox to calm quiet respiration without paradox, which almost always follows the use of these methods, is most striking.

SEDATION.-The natural instinct of the medical attendant caring for these patients is to sedate them. This is particularly so when restlessness is a problem. It is our experience that distressing symptoms such as restlessness have a definite cause (very often airway obstruction), and it is far more important to find and eradicate the cause than to sedate the patient.

The relief of pain and discomfort afforded the patient merely by abolishing paradox and thereby splinting the rib fragments is so remarkable that little analgesia is required.

Bronchial ObStruction.-The most fundamental of the principles of management of a chest injury is that the airway must be clear. It is impossible to describe the enormity of the task in observing this principle in Case 2 .

The difficulties were met with at three stages: (1) The first six hours: We have outlined and emphasized the difficulties experienced before, during, and immediately after operation. Further comment is unnecessary. (2) The first post-operative week: Throughout this week intrabronchial secretions were excessive. The factors responsible were inhalation pneumonia with a solid right lung and patchy consolidation of the left, due to the initial flooding of the bronchial tree with blood 
and vomit, intense generalized persistent bronchospasm, and severe purulent tracheobronchitis.

It was a full-time task for relays of doctors to attend to the patient during this stage. During the first week the cough reflex was of no value and suction (with sterile nylon catheters) had to be supplemented with the occasional bronchoscopy. Each new man or woman on duty found the task a difficult one and each had to be coached in the correct method of inserting the catheters into both right and left bronchi. Suction was necessary every half-hour and often more frequently. Bronchospasm was ultimately controlled with the help of an aminophylline drip. The spasm was always accentuated immediately after suction, but this was regarded as inevitable, as the secretions had to be removed.

During the second and third post-operative weeks further troublesome factors appeared. They were the inhalation of gastric contents, the pyogenic membrane in the tracheobronchial tree, and the left pleural effusion.

It might appear at first to be a fundamental breach of treatment to allow the inhalation of gastric contents. For the first week the patient was maintained on intravenous fluids, as the gastric aspirate was copious and offensive. Throughout this period saliva continued to appear at the tracheostomy, having dropped through the cords and passed through the large tracheal opening above the cuff. This saliva was always carefully removed and the pharynx aspirated before the routine hourly deflation of the cuff on the endotracheal tube.

At the end of a week the patient was able to take sips, but so long as the cuff was inflated most of each sip appeared at the tracheostomy. Each time anything was given by mouth the cuff was deflated, but co-ordination was poor and small amounts always dropped into the trachea. A Ryle's gastric tube was reverted to, but no amount of vigilance prevented the patient from pulling it out soon after it was inserted. For this reason it was inserted every four hours. It was just after the passage of this at 11 p.m. on the ninth post-operative day that the patient vomited and inhaled a dangerous amount of vomit.

At a still later stage the crusts from the pyogenic membrane created further difficulties.

It was our object from the start to remove the cuffed tube at the earliest possible moment to prevent pressure necrosis and its sequelae in the trachea. The cuffed tube was finally removed on the fourteenth post-operative day.

Throughout the period of artificial respiration the inspired air and gases were humidified.
Alevaire with or without a bronchodilator helped considerably to keep the bronchial secretions moist and mobile.

We have come to appreciate the difficulties in recognizing airway obstruction. None of the longestablished signs may be present. In Case 3, the patient almost lost his life because of our failure to recognize airway obstruction. This patient went into circulatory failure and exhibited none of the usual signs of airway obstruction. Tracheal suction made no difference. It was only when increased resistance to manual inflation was noted that the cuffed tube was removed and the obstruction found.

A similar episode occurred in one of our patients, J.K., a boy aged 14 , with severe tetanus. In the third week while under curare and controlled respiration his condition suddenly deteriorated. There was no sign of airway obstruction and routine tracheal suction was unavailing. The cuffed tube was removed and there was the soft but firmly adherent plug of secretion in the end of the tube. At this moment cardiac arrest occurred. Cardiac massage through the left chest was done in the ward, another cuffed tube was inserted, and respiration restarted. He recovered and now six months later is well.

Restlessness as an early sign of airway obstruction is very common. The moment the patient begins to fidget it should be remembered. We have found this a valuable working rule. Our feeling is that if things are not right the airway first of all must be suspected. It is our routine to remove the cuffed tube and suck out through the tracheostomy, if necessary with large metal pharyngeal suckers. This is more rapidly done than bronchoscopy, is probably more effective, and, if done carefully, no more traumatic. We frequently find secretions of blood, mucus, or fibrin adherent to the end of the cuffed tube, and they allow the sucker to pass but themselves remain attached. It often takes a brisk rub with a brush to remove them.

Defective cuffed tubes are dangerous where the cuff herniates to one side. The lumen in these tubes is easily occluded.

Pressure necrosis from the cuffed tube is a danger and constantly in the forefront of our thoughts. Windsor, M. F. (1958), reported the occurrence of tracheo-oesophageal fistula $1 \mathrm{~cm}$. in diameter in a woman of 65 years. She had severe tetanus, had been curarized, and had been on controlled respiration for five weeks. The fistula was successfully closed after a cervical exploration. Maxwell (1960) has reported a fatal haemorrhage from a necrotic ulcer in the tracheal wall in a patient, a 
woman aged 32 years, suffering from bulbar palsy. She had been on mechanically assisted respiration for three weeks.

A strict routine must be adopted so that the cuffed tube is a snug fit without being tight; cuff inflation must render the circuit just airtight; and deflation of the cuff, preceded by pharyngeal and tracheal suction for five minutes every half-hour, is imperative.

Even when paradox is severe (Case 7), the chest wall, once it is stabilized, begins to harden with great rapidity, sometimes in a few days. As soon as this happens we stop the respirator and deflate the cuff. Certainly paradox is still present, but usually of little clinical significance, and it is not often that a return to the respirator is necessary.

Additional Features.-We have not previously encountered the pathological state found in Case 6. A virtual explosion had taken place within the lobe, resulting in disruption and cavitation. Despite this the visceral pieura remained intact. The lobe was a blood-containing cavity, yet at no stage did the patient have a haemoptysis. This, together with the radiographic increase in the gas, suggested a pre-operative diagnosis of traumatic diaphragmatic hernia, although we had never seen bowel presenting posteriorly in the right side of the chest following injury.

The phenomenon of the response of the central nervous system to adequate respiratory interchange as demonstrated in Case 8 is a feature which we note with increasing frequency. A similar phenomenon has been a gratifying experience on a number of occasions after tracheostomy had been performed in the management of cases of cerebral trauma.

Severe violence, multiple injuries, and an elderly subject (Case 3 ) is a combination which really taxes the resources of a hospital. Survival rates with controlled or assisted respiration are in striking contrast to mortality rates before such methods were available.

\section{CONCLUSION}

There are certain general considerations upon which we wish to comment.

The severe case is and will remain an almost purely clinical problem. The changing patterns occur with great rapidity and at any time, and the clinician must be able to recognize them without the help of the laboratory, for frequently they need immediate attention.
These changing patterns demand constant vigilance by experienced observers. We believe (and practise) that while respiration is being assisted a doctor must be present. On three occasions (Cases 2, 3, and J.K., a boy with tetanus) life was saved by attention to this rule.

In Australia, a country of long distances, we have learned that patients with severe chest injuries, no matter what the risk, must be transferred to a large unit. Vigilance can only be supplied by a large thoracic unit. (We are indebted to the R.A.A.F., which is always ready to take us to or bring patients from inaccessible places.) An intercostal catheter can be inserted, a tracheostomy can be done, and assisted respiration can be started anywhere, but they cannot be supervised anywhere.

We have recently had the experience of trying to sustain life in a native woman from Trobriand Island, who developed a post-operative tuberculous spread in the right lung following removal of her destroyed left lung. In the first two postoperative days convalescence was uneventful, but as the right lung became more opaque respiration became more difficult. Very soon mechanically assisted respiration was no longer of avail. Life, however, was sustained for a further three days by manually controlled respiration with high inflationary pressures. Efforts were only discontinued when these pressures burst the lung.

The point we wish to make is that the perfect respirator has not yet been made. There are many good ones, but where severe paradox, atelactasis, and bronchospasm are combined, none of them can compare with manual inflation. That this is laborious we concede. That it will save many crushed chests we are convinced.

We should like to thank the editor of the Australian and New Zealand Journal of Surgery for permission to quote extensively from the February, 1960, issue.

\section{REFERENCES}

Avery, E. E., Mörch, E. T., and Benson, D. W. (1956). J. thorac, Surg., 32, 291.

Barford, J. L. (1906). Lancet, 2, 1509.

Bickford, B. J., and Robertson, P. W. (1958). Thorax, 13, 246.

Dark, J., and Dewsbury, P. (1955). Ibid., 10,62.

Maxweli, D. (1960). Personal communication.

Moty and Guibal (1907). Arch. Méd. Pharm. milit., 1, 444.

Moty and Guibal (1907). Arch. Med.

Patrick, J. (1917). Brit.med. J., 2, 359.
Richards, V., and Cohn, R. B. (1955). Amer. J. Surg., 90, 253.

Rolleston, H. D. (1891). Trans. path. Soc. Lond., 42, 42.

Schönberg, S. (1912). Berl. klin. Wschr., 49, 2218.

Seuvre (1873). Bull. Soc. anat. Paris, 48 (5 ser., 8), 680.

Thompson, J. V., and Eaton, E. R. (1955). J. thorac. Surg., 29, 260.

Windsor, H. M., and Dwyer, B. (1960). Aust. N.Z. J. Surg., 29, 235.

Windsor, M. F. (1958). Personal communication. 